\title{
Consequences of Postnatal Stress: Maternal Separation in Rats Induces Long-Lasting Changes on Glutamate Transporters
}

\author{
María Mercedes Odeon ${ }^{1}$, Adrián Emanuel Salatino ${ }^{1}$ and Gabriela Beatriz Acosta ${ }^{1,2 *}$
}

${ }^{1}$ Institute of Pharmacological Research (ININFA), National Scientific and Technologic Research Council (CONICET), Buenos Aires, Argentina

${ }^{2}$ Department of Physiopathology, School of Pharmacy and Biochemistry, University of Buenos Aires, Junín 956, 5th Floor C1113AAD, Buenos Aires, Argentina

\begin{abstract}
Background: There is increasing evidence that environmental factors, particularly stressful events experienced early in life, increase the risk of developing a psychiatric illness and/or a behavioural disorder. The aim of this study was to evaluate the effects of acute and chronic maternal separation (AMS and CMS) plus cold stress on the expression patterns of Glutamate Transporters (TGlus) in the developing and young adult Central Nervous System (CNS). As regulation of Glutamate (Glu) extracellular levels is of key importance, sodium-dependent Glu uptake using synaptosome-enriched fractions isolated from Frontal Cortex (FC) and Hippocampus (Hic) was also studied.
\end{abstract}

Results: In animals under AMS stress found that Glu uptake decreases with respect to control groups. Meanwhile in CMS did not observe changes on Glu uptake in adult animals. These data would suggest the existence of an adaptive mechanism that could compensate the effect of AMS and CMS plus cold stress on glutamate uptake. Western blotting was performed in homogenates prepared from FC and Hic from both neonate and young adult rat brains. These blots exposed that homogenates include GLT-1 and EAAC-1 proteins and their levels varied in different areas of the rat brain and with the age of animals.

Conclusions: During early postnatal life, exposure to various stressors lead to the development of various neurological, psychiatric, neurodegenerative and behavioral disorders, expressible in adult life in the case of chronic stress.

These results demonstrate that adverse early life events have profound and persistent effects on brain function and may represent a risk factor for the development of psychopathology later life.

Keywords: Acute; Chronic; Maternal separation; Cold stress; Glutamate transporters; Uptake; Western blot

\section{Introduction}

Studies in animal models show the influence of life conditions during the postnatal period in the establishment of neurological factors that control behaviour and response to stress [1]. Acute and chronic maternal separation plus cold stress has both short and long term effects on behavioural and neuroendocrinal responses [2]

Early adverse life events constitute one of the major risk factors for the development of mental disorders, such as anxiety, post-traumatic stress disorder, and major depression. Moreover, it may also increase an individual's vulnerability to substance abuse latter in adult life [3]. Several animal models have been used to elucidate the functional and biochemical consequences of early life adversity, and have revealed a number of persistent effects including changes in the activity of the Hypothalamic-Pituitary-Adrenal (HPA) axis [4,5].

Events occurring early in life, acting through abnormal maternal hormones and/or maternal behaviour, can alter the trajectory of the programming of the HPA axis response to stress. For example, it has been demonstrated that increased mothering behaviour produces stable alterations in DNA methylation and chromatin structure [5] inducing increased transcription of Glucocorticoid Receptor (GR) gene, important for the HPA axis feedback loop [6].

The occurrence of adverse conditions during development, such as pre or postnatal stress, induced changes in the animal's stress response for their whole lifespan [7]. Certain brain regions, mainly those related to the processing of adverse situations, such as FC, Hic and the HPA axis, during their critical periods, can develop abnormalities that are sometimes irreversible and thus alter emotional processes and response to stress throughout the animal's life [8].
Many studies indicate that the physical stress have established a relation between MS and cold stress. For example, Zimmerberg and Shartrand [9] demonstrated that young rats subjected to cold stress were developmentally delayed and had lower body and brain weight. These animals also showed altered responsiveness and dopaminergic system function in relation to pups kept with the mother or separated but placed at nest temperature. Furthermore, others authors showed that midbrain endorphin levels were decreased after isolation [10]. Ibarra et al. [11] suggested that both isolation and modification of temperature environment could affect several neurochemical parameters (such as dopaminergic system, endorphin levels and total RNA synthesis) which could trigger profound behavioural alterations not only during early life but also in adulthood.

Postnatal stress and particularly Maternal Separation (MS), shows a variety of long term neurochemical, hormonal and behavioural effects. Manipulations such as prolonged MS of pups from the dam have been used as an animal model of early-life trauma [12]. Animal models are quite useful for elucidating the mechanisms underlying abnormalities toward possible treatment strategies for psychiatric, emotional or neurological diseases [13-15]. Different experimental protocols of MS

*Corresponding author: Gabriela Beatriz Acosta, Junín 956, $5^{\text {th }}$ Floor, C1113AAD Buenos Aires, Argentina, Tel: 54-11-4961-5949/6784; Fax: 54-11-4963-8593 E-mail: gacosta@ffyb.uba.ar

Received January 11, 2013; Accepted March 02, 2013; Published March 05 2013

Citation: Odeon MM, Salatino AE, Acosta GB (2013) Consequences of Postnata Stress: Maternal Separation in Rats Induces Long-Lasting Changes on Glutamate Transporters. Clin Exp Pharmacol 3: 121. doi:10.4172/2161-1459.1000121

Copyright: ( 2013 Odeon MM, et al. This is an open-access article distributed under the terms of the Creative Commons Attribution License, which permits unrestricted use, distribution, and reproduction in any medium, provided the original author and source are credited. 
in rats have shown changes in CNS functioning: learning impediments, voluntary alcohol consumption and behavioural variations. Several lines of evidence suggest that increases in extracellular levels of Glu are involved in the stress response [16].

Glu is the major excitatory neurotransmitter in the mammalian CNS and plays a key role in synaptic plasticity and learning. Throughout development, a connecting mechanism may exist that links NMDA receptor activation to changes in dendritic morphology and afferent connectivity $[17,18]$. A tight control of Glu extracellular levels is crucial for the correct functioning and development of central synapses and neural circuits. Extracellular concentrations of Glu are strictly regulated by transporter proteins expressed in the plasma membrane of both neurons and glial cells $[19,20]$. A family of $\mathrm{Na}^{+}-$ dependent transporters is of prominent importance for Glu uptake and for regulating homeostasis in CNS [21-23]. Up-date, five high-affinity Glutamate Transporters (TGlus) have been cloned from human and animal tissues, and they are identified as GLAST (EAAT-1) [24,25], GLT-1 (EAAT-2) [24,25], EAAC-1 (EAAT-3) [24,26-28], EAAT-4 $[24,28,29]$ and EAAT-5 [30,31]. In the remainder of the text, we shall use the abbreviation TGlus when referring to a glutamate transporter in a generic manner or to all glutamate transporters as a group.

Previous studies have indicated that exposure to variable types of stressors during development produces persistent behavioral defects that are associated with hormonal, neurotransmitters, transporters and functional changes, and resemble an array of psychopathological conditions. Hence, the aim of the present work was to study the consequences of AMS or CMS plus cold stress and to describe the expression patterns and regulation of TGlus activity during development and in different maturation stages of FC and Hic. Also we evaluated the effects of early life environmental interventions during neonatal period involved 1 hour duration of mother-infant separation.

\section{Experimental Procedures}

\section{Animals}

We used Male Wistar rats. They were kept in a climate controlled animal room, at a constant temperature of $21-23^{\circ} \mathrm{C}$, mantained on a 12-hour light-dark cycle with ad libitum access to dry food and tap water. All animal procedures were performed in accordance with our institutional guidelines and with the U.S. National Institute of Health Guide for the Care and Use of Laboratory Animals (NIH publication N8 80-23/96), after obtaining approval from the Institutional Animal Ethics Committee. All efforts were made to minimize animal suffering, and to reduce the number of animals used.

\section{Maternal separation}

Rat pups subjected to MS were separated from their mother at postnatal day-(PD) (PD1 is the day after birth) PD5, PD7 and PD13 and were placed in separation cages for $1 \mathrm{~h}[32,33]$. Litters were of 1011 pups. Control pups were left undisturbed with their mothers. All pups were weaned on day 21 .

The separation cages were lined with $3 \mathrm{~cm}$ bedding material so that pups could further thermoregulate by huddling with littermates and burrowing into bedding. Studies show that, under similar conditions, pup core temperature is maintained, indicating effective behavioral thermoregulation [34]. After 1h, pups were returned to the home cage with their mother. In control litters, pups remained with the dams undisturbed until weaning age at PD21, except for routine cage cleaning. These animals constitute the best control group for investigations of the effects of MS [12]. After weaning, rats were housed in same sex groups under standard conditions.

\section{AMS and CMS plus cold stress protocols}

To evaluate the effect of AMS plus cold stress rat pups were separated from their mother and exposed to cold $\left(4^{\circ} \mathrm{C}\right)$ during $1 \mathrm{~h}$ [33]. Neonates were placed together in a small cage. Application of cold stress usually started at 10:00 hs. No mortality was observed in this group.

\section{AMS+cold stress:}

a) Control group: Neonates remained with their mother.

b) Stressed group: Neonates were separated from their mother at PD5, PD7, PD13 and exposed to cold stress $\left(4^{\circ} \mathrm{C}\right)$ for $1 \mathrm{~h}$. Pups were then killed by decapitation immediately after the stress session.

\section{CMS + cold stress}

a) Control group: Neonates remained with their mother.

b) Stressed group: Neonates were separated from their mother at PD5, PD7, PD13 and exposed to cold stress $\left(4^{\circ} \mathrm{C}\right)$ for $1 \mathrm{~h} /$ day for 20 days. After 20 days of stress the animals remained in their cages for 30 days (washout period). The young adult animals were sacrificed by decapitation at PD55, PD57, PD63. a)

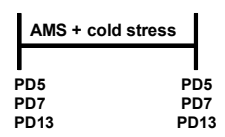

b)

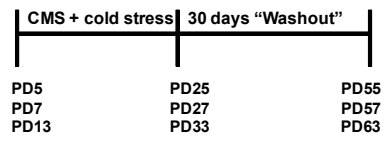

\section{Tissue samples preparation and $\left[{ }^{3} \mathrm{H}\right] \mathrm{L}-\mathrm{Glu}$ uptake}

After decapitation, brains were removed from the cranial cavity; FC and Hic were dissected on a Petri dish at $0^{\circ} \mathrm{C}$, according to Glowinski and Iversen [35] and homogenized with a glass-PTFE homogenizer in $20 \mathrm{ml}$ of $0.32 \mathrm{M}$ sucrose/ $1 \mathrm{~g}$ tissue. The homogenates were centrifuged at $800 \mathrm{~g}$ for $15 \mathrm{~min}$, the pellet was discarded and the supernatant was centrifuged at 20,000 g for $20 \mathrm{~min}$. The pellet $(\mathrm{P} 2=$ crude synaptosomal fraction) was suspended with a glass-PTFE homogenizer in fresh Krebs buffer and again centrifuged at 20,000 g for $20 \mathrm{~min}$. This procedure was repeated three times; the resulting pellet was re-suspended and was used in uptake experiments within 5 hrs of preparation [33,36]. Time course experiments were performed to demonstrate that Glu uptake is linear until 5 min (data not shown).

Determination of $\mathrm{Na}^{+}$-dependent high-affinity Glu uptake was performed as described by Odeon et al. [33]. Uptake experiments were carried out using fresh synaptosome enriched fractions at a concentration of $20 \mathrm{mg}$ of the original tissue (wet weight) per $1 \mathrm{ml}$ of incubation medium. This consisted of $125 \mathrm{mM} \mathrm{NaCl}, 3.5 \mathrm{mM} \mathrm{KCl}, 1.5$ $\mathrm{mM} \mathrm{CaCl}_{2}, 1.2 \mathrm{mM} \mathrm{MgSO}_{4}, 1.25 \mathrm{mM} \mathrm{KH}_{2} \mathrm{PO}_{4}, 25 \mathrm{mM} \mathrm{NaHCO}_{3}, 10$ $\mathrm{mM}$ HEPES and $10 \mathrm{mM}$ D-glucose, $\mathrm{pH}$ adjusted to 7.4. Uptake assays were started by adding $\left[{ }^{3} \mathrm{H}\right] \mathrm{L}-\mathrm{Glu}$ at $10^{-6} \mathrm{M}$ final concentration (specific activity: $46.9 \mathrm{Ci} / \mathrm{mmol}$ ) diluted in the buffered physiological medium. Incubations were performed at $30^{\circ} \mathrm{C}$ for 1 to $40 \mathrm{~min}$. The incubation was terminated by vacuum-filtration through Whatman glass fiberfilters (type D) and three rapid washes with isotonic saline solution (at $2-4^{\circ} \mathrm{C}$ ). Using the known specific activity, the net uptake of Glu by the synaptosomes was calculated, and expressed as fentomoles $/ \mathrm{mg}$ protein/min. Parallel experiments were always performed without any incubation, as time 0 , to assess non-specific radioactivity not retained 
by FC and Hic preparations, for the radiolabeled substrate used. All measurements were made in triplicate. Protein content was estimated by the Lowry technique [37] using bovine serum albumin as standard.

\section{Electrophoresis and western blotting}

Western blotting analysis was used to measure levels of GLT-1 and EAAC-1 expression in Hic and FC. Both areas were dissected on a Petri dish at $0^{\circ} \mathrm{C}$ and homogenized with a glass-PTFE homogenizer in lysis buffer (Tris Base $50 \mathrm{mM}$; NaCl $150 \mathrm{mM}$; EDTA $2 \mathrm{mM}$; SDS 0.05\%; Triton-X100 1\%, PMSF $100 \mathrm{~g} / \mathrm{ml}$; Leupeptin $1 \mu \mathrm{g} / \mathrm{ml})$. Protein concentration in the samples was analysed by the Lowry technique [34]. Aliquotes (total proteins $20 \mu \mathrm{g}$ ) were separated on $12 \%$ Sodium Dodecyl Sulfate-Polyacrylamide Gel (SDS-PAGE) at $130 \mathrm{~V}$ and transferred to a nitrocellulose membrane using a blot system (Transblot, BioRad). The membranes were incubated in blocking buffer (1 X TBS and 5\% non-fat dry milk) for $1 \mathrm{~h}$ at Room Temperature (RT) and afterwards incubated overnight at $4^{\circ} \mathrm{C}$ with one of the following specific primary antibodies: guinea pig anti-GLT-1(1:500), rabbit anti-actin (1:1000) or rabbit anti-EAAC1 (1:500). Blots were then washed three times for $10 \mathrm{~min}$ in $1 \mathrm{X}$ TBS with $0.3 \%$ Tween 20 at RT and then incubated for $1 \mathrm{~h}$ at RT with goat anti rabbit IgG (1: 2000) or goat anti-guinea pig (1:2000) conjugated to horseradish peroxidase. They were then washed three times for 10 min in 1 X TBS with $0.1 \%$ Tween 20 at RT. Inmunodetection of bands was accomplished using the Pierce Super Signal Chemiluminescence Kit (ECL, Pierce) and further exposure on X-ray film (Agfa) (Figure 3). For quantification of band intensity, blots were scanned and analyzed using Image J PC software analysis. The expression level corresponds to the number of black pixels of each band. The results were expressed as Optical Density (OD) in arbitrary units. Actin was used as a loading control. The amount of protein was analysed as a ratio between the protein and actin, to ensure that an equal amount of protein was loaded onto the gel and transferred to the membrane.

\section{Statistical analysis}

All data are expressed as mean \pm Standard Error Of The Mean (S.E.M.) ANOVAs revealing significant effects $(\mathrm{P}<0.05)$ were followed by post-hoc Tukey's test [38].

\section{Sources of materials}

$\left[{ }^{3} \mathrm{H}\right] \mathrm{L}-$ Glutamate (specific activity: $46.9 \mathrm{Ci} / \mathrm{mmol}$ ) was from Perkin Elmer, NEN, Life Science Inc. (Boston, MA, USA). L-TGluamate, Phenymethanesulfonyl Fluoride (PMSF), Leupeptine were from Sigma Chemical Co. St. Louis, MO, USA. Kit ECL Western blotting substrate was from Pierce, Thermo Scientific IL-USA. Primary antibodies: aGLT1, guinea pig (AB1520) from Millipore Chemicon, USA and aEAAT3, rabbit (sc-25658) from Santa Cruz Biotechnology, INC. California, USA; aActin, rabbit (A2066) was from Sigma Chemical Co. St. Louis, MO, USA . Secondary antibodies: arabbit- and aginea pig-were from Santa Cruz.

\section{Results}

\section{Studies of $\left[{ }^{3} \mathrm{H}\right] \mathrm{L}$-Glutamate uptake}

We analyzed the effects of either AMS or CMS groups plus cold stress on the $\mathrm{Na}^{+}$-dependent uptake of Glu by FC and Hic synaptosomes, both early in postnatal development and in young adult rats (data not shown). We found that the uptake of Glu did not modify in both areas at all ages studied in CMS. While we found significant decreases induced by acute treatment in FC at PD5 and PD7. Comparing the chronic results with those obtained after acute stress, shows that repeated exposure to maternal separation and cold for 20 days has a different effect than when exposed only once.

Not differences observed after a chronic exposure to the stressful stimuli, can be explained by the fact that functional activity of transporter proteins are often regulated by rapidly changing their expression in the plasma membrane.

Molecular characterization of $\mathrm{Na}^{+}$-dependent high affinity TGlus: EAAC-1 and GLT-1 in FC and Hic homogenates

Western blotting was performed in homogenates prepared from FC and Hic from both neonate and young adult rat brains. These blots reveal that the homogenates include GLT-1 and EAAC-1 proteins (Figure 1 and 2). GLT-1, often described as the glial-specific TGlus $[39,40]$, accounts for more than $90 \%$ of the total Glu uptake, and is an essential contributor to TGlus homeostatic role as well as EAAC-1 has been found predominantly in neurons $[19,20]$.

Our results shown that in AMS group, there was a significant increase in GLT-1 both at PD5 $(21 \%, \mathrm{P}<0.05)$ and PD13 $(34 \%, \mathrm{P}<0.05)$ in $\mathrm{FC}$, while in Hic there was only increase at $\mathrm{PD} 7(30 \%, \mathrm{P}<0.05)$ in the levels of protein transporter (Figure 1A). Though, in CMS group, we found a significant increment in GLT-1 no more than at PD57 (42\%, $\mathrm{P}<0.05)$ in FC (Figure 1B).

In all samples run Glial Fibrillary Acidic Protein (GFAP) protein was found. Not changes in Western blott were produced by either treatment at different ages studied. This ensures that the samples obtained from brain homogenates contained a glial fraction. Furthermore seeing no significant differences in levels of the marker, we could suppose that the differences found in GLT-1 levels were not due to changes in the number of glial cells.

Western-blotting showed that a significant reduction in EAAC-1 expression in FC in AMS treatment at PD13 (38\%, P<0.01). In Hic, AMS
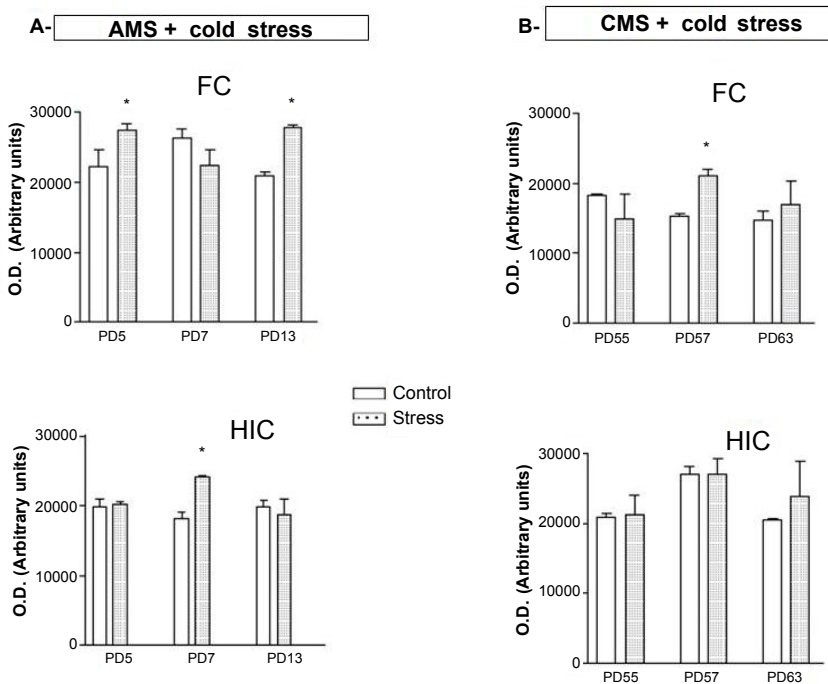

Figure 1: Western blotting analysis of GLT1 (MW: $~ 52 \mathrm{kDa}$ ) in FC and Hic homogenates from $A$ : unstressed group and AMS+cold stress group. B: unstressed group and $\mathrm{CMS}+$ cold stress group. Band densities were quantified and are shown as a bar chart. The expression level corresponds to the number of black pixels of each band counted using Image $\mathrm{J}$, data are quoted as the mean \pm SEM. Actin (MW: $\sim 42 \mathrm{kDa}$ ) served as a loading control. GFAP (MW: $49 \mathrm{kDa}$ ) served as glial marker. Western blots are representative of 3 different experiments. OD:optical density, arbitrary units. ${ }^{*} p<0.05 ;{ }^{* *} p<0.01$ compared with the respectively unstressed group. 


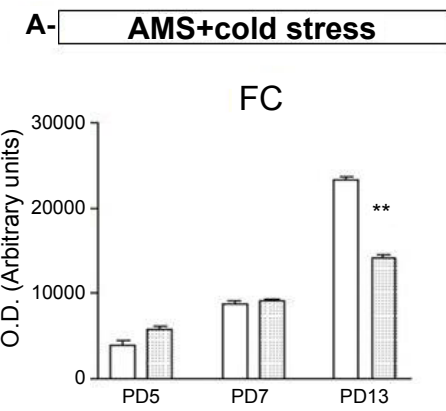

\section{B- CMS +cold stress}


\%

HIC

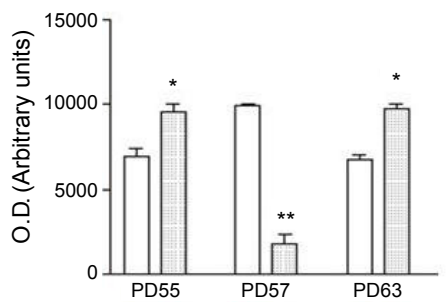

Figure 2: Western blotting analysis of EAAT3 (MW: $57 \mathrm{kDa}$ ) in FC and Hic homogenates from A: unstressed group and AMS+cold stress groups. B: unstressed group and CMS+cold stress group. The expression level corresponds to the number of black pixels of each band counted using Image $J$, data are quoted as the mean \pm SEM. Actin (MW: $\sim 42 \mathrm{kDa}$ ) served as a loading control. Western blots are representative of 3 different experiments. OD: optical density, arbitrary units. ${ }^{*} p<0.05 ;{ }^{* *} p<0.01$ compared with the respectively unstressed group.

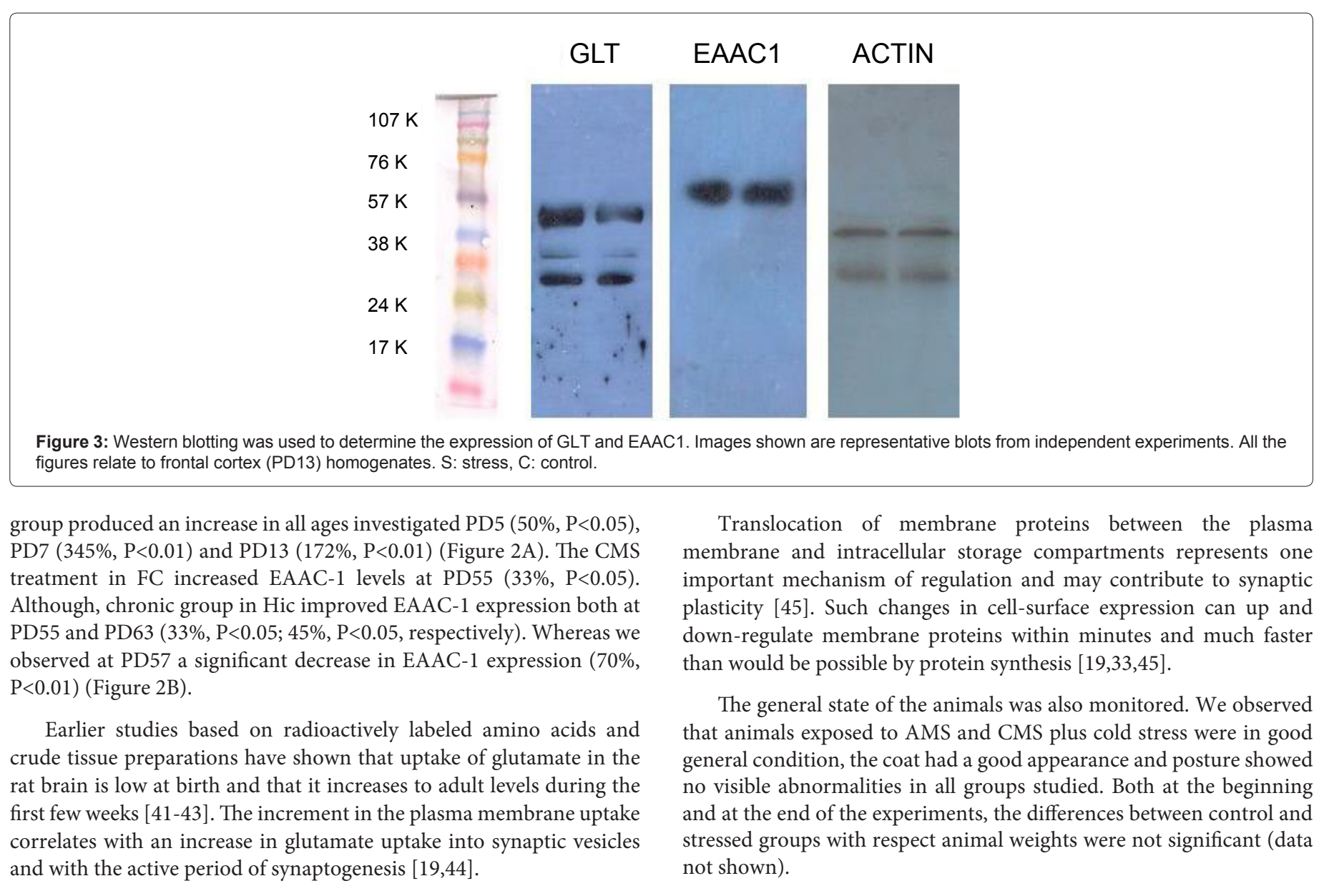




\section{Discussion}

The adaptability of the organism and its ability to build new strategies or operating conditions in response to stimuli, both external and internal, allows the continuation of life under adverse situations [46]. During postnatal development, the CNS is highly sensitive to the effects of drugs, stressors and environment $[46,47]$.

We cannot considerate the cold exposure such us a separate factor in this study. Exposure to cold can produce a variety of injuries that occur as a result of individual's inability to adapt to cold. These injuries can be divided into localized injury to a body part, systemic hypothermia, or a combination of both.

In the acute treatment, we saw that the effect varies with the age at which the stressor is applied. It finds its cause in the fact that each structure has a different pattern of maturation. Glutamatergic transmissions mature at different times depending the brain structure [48]. The effects AMS plus cold stress are seen in FC at PD5 and PD7, a time when the cortex is under development, and is therefore more vulnerable, while days later this effect is not observed. In Hic these special effects are not focused, might be due to low glutamatergic activity sensible in this area during the first weeks postpartum; this reduces their vulnerability. The consequence being more damaging when this transmission is at its maximum development.

In chronic treatment, the absent of changes in Glu uptake was induced by either stage of development or brain areas studied. These findings are in agreement with the hypothesis of compensatory changes which develop in response to repeated stress exposure. The time-dependent alterations might reflect adaptative processes [49]. We saw that a single presentation of the stimulus has an effect on the uptake, this protocol is repeated in this exposure for 20 days, long enough to allow the animal to adapt to that context and compensate by some other mechanism. The CNS maintains a degree of adaptive plasticity, which allows it to adjust to certain circumstances and modify the innate patterns of neural connections.

Therefore, with these references, we can infer that the effects of AMS+cold stress on TGlus showed a decrease uptake of Glu in developing structures, as yet have not all the synaptic connections that have this structure in the adult animal.

The effect of CMS plus cold stress in FC appears a dramatic increase occurred one month after the exposure to cold stress. This variation in a few days can be natural. In fact it is what we think that it happens, because it occurs both in controls and in the stressed groups. They are a few days but there is possible this percentage of adjustment of a natural way. This down-regulation was found to be associated with a movement of the transporters from the plasma membrane to intracellular compartments. Evidences suggest that a protein kinase $\mathrm{C}$ (PKC) does not directly phosphorylate GLT-1 and EAAC-1, but rather alters indirectly the distribution of both transporters in the plasma membrane and intracellular vesicles [50,51].

As regards the expression of specific types of TGlus, previous reports show that the expression level of GLT-1 was found to progressively increase into adulthood [40,52,51]. However, expression of EAAC-1 was greater in the newborn brain compared with the adult brain. These results provide direct evidence that GLT-1 and EAAC- 1 are necessary for brain development $[45,53,54]$. Our data indicate that the effects of neonatal isolation persist post-weaning and are most evident when associated to a second stressful stimulus such as low temperature.
Ellenbroek and Cools [55] showed that early maternal deprivation induced schizophrenia-like abnormalities in adult Wistar rats, but not in Fischer 344 or Lewis rats. These results provide strong support for the general hypothesis that genetic and environmental factors may contribute to the overall development of the brain, and can also affect brain function, suggesting that maternal deprivation may represent a novel and very interesting tool for studying the interaction between genetics and early stressful life events.

The early postnatal period and the bond between mother and infant seem particularly important in the development and shaping of normal stress response and emotional behaviour [53-55]. While the mechanisms underlying the long-term effects of environmental stress early in life are not known, they are likely to involve activation of intracellular signalling pathways, leading to modifications of the genome, resulting in changes in gene expression and neural function [56]. The neural changes underlying the persistent effects of early life separation and stress in rodents remain to be fully elucidated.

\section{Conclusions}

The present study shows that the glutamate transporters are affected by AMS and CMS plus cold stress in certain areas of the brain and different ages of development.

Postnatal stress induces several early changes in biological systems that occur instantaneously. Regarding high-affinity $\mathrm{Na}^{+}$-dependent Glu uptake, when we investigated CMS plus cold stress in FC and Hic we did not find any change. While in AMS treatment we observed significant decrease. TGlu modifications would produce an increase in Glu concentration in the extracellular space and this effect would produce neurotoxic, therefore, these fluctuations may have significant consequences in the glutamatergic synaptic signals. In what follows then, that the Glu uptake has a protective effect and in fact its blockade promotes neurodegeneration.

The present findings have clearly demonstrated that animals exposed to extremely traumatic stressful situations, such as AMS and CMS plus cold stress, exhibit a variety of long-lasting bidirectional neurochemical abnormalities, which could correlate with the symptoms observed in human patients with neurological, emotional or cognitive diseases [57]. Atleast, maternal interaction and early stressful events may affect regulation of the HPA axis during adulthood, leading to differential glucocorticoid secretion in response to stressful situations. These adverse experiences during postnatal development may even sensitize specific neurocircuits to subsequent stressors. Later in life, the overreaction of the HPA axis to stress can constitute a risk factor for metabolic and mental diseases. Maternal separation is not only the adaptation problem, but also developmental and survival strategy problem.

\section{References}

1. Marco EM, Adriani W, Llorente R, Laviola G, Viveros MP (2009) Detrimenta psychophysiological effects of early maternal deprivation in adolescent and adult rodents: altered responses to cannabinoid exposure. Neurosci Biobehav Rev 33: 498-507.

2. Anisman H, Zaharia MD, Meaney MJ, Merali Z (1998) Do early-life events permanently alter behavioral and hormonal responses to stressors? Int J Dev Neurosci 16: 149-164.

3. Plotsky PM, Meaney MJ (1993) Early, postnatal experience alters hypothalamic corticotropin-releasing factor (CRF) mRNA, median eminence CRF content and stress-induced release in adult rats. Brain Res Mol Brain Res 18: 195-200.

4. Ladd CO, Huot RL, Thrivikraman KV, Nemeroff CB, Plotsky PM (2004) Longterm adaptations in glucocorticoid receptor and mineralocorticoid receptor 
mRNA and negative feedback on the hypothalamo-pituitary-adrenal axis following neonatal maternal separation. Biol Psychiatry 55: 367-375

5. Weaver IC, Cervoni N, Champagne FA, D'Alessio AC, Sharma S, et al. (2004) Epigenetic programming by maternal behavior. Nat Neurosci 7: 847-854

6. Meaney MJ, Szyf M (2005) Environmental programming of stress responses through DNA methylation: life at the interface between a dynamic environment and a fixed genome. Dialogues Clin Neurosci 7: 103-123.

7. McEwen BS (2007) Physiology and neurobiology of stress and adaptation central role of the brain. Physiol Rev 87: 873-904.

8. Weiss MJ, Wagner SH (1998) What explains the negative consequences of adverse childhood experiences on adult health? Insights from cognitive and neuroscience research. Am J Prev Med 14: 356-360.

9. Zimmerberg B, Shartrand AM (1992) Temperature-dependent effects of maternal separation on growth, activity, and amphetamine sensitivity in the rat. Dev Psychobiol 25: 213-226.

10. Shoemaker WJ, Kehoe $P$ (1995) Effect of isolation conditions on brain regional enkephalin and beta-endorphin levels and vocalizations in 10-day-old rat pups. Behav Neurosci 109: 117-122.

11. Ibarra GR, Paratcha GC, Rodriquez JA, Napp MI, Azcurra JM (1997) Cold stress related alteration of RNA biosynthesis in brain cortex of mother-deprived newborn rats. Life Sci 60: 2165-2171.

12. Lehmann J, Feldon J (2000) Long-term biobehavioral effects of materna separation in the rat: consistent or confusing? Rev Neurosci 11: 383-408.

13. O'Shea RD (2002) Roles and regulation of glutamate transporters in the central nervous system. Clin Exp Pharmacol Physiol 29: 1018-1023.

14. Yehuda R, Antelman SM (1993) Criteria for rationally evaluating animal models of posttraumatic stress disorder. Biol Psychiatry 33: 479-486

15. Tamaki K, Yamada K, Nakamichi N, Taniura H, Yoneda Y (2008) Transient suppression of progenitor cell proliferation through NMDA receptors in hippocampal dentate gyrus of mice with traumatic stress experience. J Neurochem 105: 1642-1655.

16. Reznikov LR, Grillo CA, Piroli GG, Pasumarthi RK, Reagan LP, et al. (2007) Acute stress-mediated increases in extracellular glutamate levels in the rat amygdala: differential effects of antidepressant treatment. Eur J Neurosci 25: 3109-3114.

17. Komuro H, Rakic P (1993) Modulation of neuronal migration by NMDA receptors. Science 260: 95-97.

18. LoTurco JJ, Blanton MG, Kriegstein AR (1991) Initial expression and endogenous activation of NMDA channels in early neocortical development. J Neurosci 11: 792-799.

19. Danbolt NC (2001) Glutamate uptake. Prog Neurobiol 65: 1-105.

20. Balcar VJ (2002) Molecular pharmacology of the Na+-dependent transport of acidic amino acids in the mammalian central nervous system. Biol Pharm Bul 25: 291-301.

21. Auger C, Attwell D (2000) Fast removal of synaptic glutamate by postsynaptic transporters. Neuron 28: 547-558.

22. Takeuchi H, Jin S, Wang J, Zhang G, Kawanokuchi J, et al. (2006) Tumor necrosis factor-alpha induces neurotoxicity via glutamate release from hemichannels of activated microglia in an autocrine manner. J Biol Chem 281 21362-21368.

23. Thomas CG, Tian H, Diamond JS (2011) The relative roles of diffusion and uptake in clearing synaptically released glutamate change during early postnatal development. J Neurosci 31: 4743-4754.

24. Shashidharan $P$, Plaitakis $A$ (1993) Cloning and characterization of a glutamate transporter cDNA from human cerebellum. Biochim Biophys Acta 1216: 161 164.

25. Yamashita A, Makita K, Kuroiwa T, Tanaka K (2006) Glutamate transporters GLAST and EAAT4 regulate postischemic Purkinje cell death: an in vivo study using a cardiac arrest model in mice lacking GLAST or EAAT4. Neurosci Res 55: $264-270$

26. Storck T, Schulte S, Hofmann K, Stoffel W (1992) Structure, expression, and functional analysis of a $\mathrm{Na}(+)$-dependent glutamate/aspartate transporter from rat brain. Proc Natl Acad Sci U S A 89: 10955-10959.
27. Bristol LA, Rothstein JD (1996) Glutamate transporter gene expression in amyotrophic lateral sclerosis motor cortex. Ann Neurol 39: 676-679.

28. Kanai Y, Hediger MA (1992) Primary structure and functional characterization of a high-affinity glutamate transporter. Nature 360: 467-471.

29. Pines G, Danbolt NC, Bjørås M, Zhang Y, Bendahan A, et al. (1992) Cloning and expression of a rat brain L-glutamate transporter. Nature 360: 464-467.

30. Pow DV, Barnett NL (2000) Developmental expression of excitatory amino acid transporter 5: a photoreceptor and bipolar cell glutamate transporter in rat retina. Neurosci Lett 280: 21-24.

31. Wersinger E, Schwab Y, Sahel JA, Rendon A, Pow DV, et al. (2006) The glutamate transporter EAAT5 works as a presynaptic receptor in mouse rod bipolar cells. J Physiol 577: 221-234.

32. Ladd CO, Owens MJ, Nemeroff CB (1996) Persistent changes in corticotropinreleasing factor neuronal systems induced by maternal deprivation Endocrinology 137: 1212-1218

33. Odeon MM, Salatino AE, Rodríguez CB, Scolari MJ, Acosta GB (2010) The response to postnatal stress: amino acids transporters and PKC activity. Neurochem Res 35: 967-975.

34. Farrell WJ, Alberts JR (2007) Rat behavioral thermoregulation integrates with nonshivering thermogenesis during postnatal development. Behav Neurosc 121: $1333-1341$

35. Glowinski J, Iversen LL (1966) Regional studies of catecholamines in the rat brain. I. The disposition of $[3 \mathrm{H}]$ norepinephrine, $[3 \mathrm{H}]$ dopamine and $[3 \mathrm{H}]$ dopa in various regions of the brain. $\mathrm{J}$ Neurochem 13: 655-669.

36. Takarada T, Balcar VJ, Baba K, Takamoto A, Acosta GB, et al. (2003) Uptake of [3H]L-serine in rat brain synaptosomal fractions. Brain Res 983: 36-47.

37. lowry OH, Rosebrough NJ, Farr AL, Randall RJ (1951) Protein measurement with the Folin phenol reagent. J Biol Chem 193: 265-275

38. Winner BJ (1971) Statistical principles in experimental design. Mc Graw Hill, New York, USA.

39. Davis KE, Straff DJ, Weinstein EA, Bannerman PG, Correale DM, et al. (1998) Multiple signaling pathways regulate cell surface expression and activity of the excitatory amino acid carrier 1 subtype of Glu transporter in C6 glioma. J Neurosci 18: 2475-2485

40. Voutsinos-Porche B, Bonvento G, Tanaka K, Steiner P, Welker E, et al. (2003) Glial glutamate transporters mediate a functional metabolic crosstalk between neurons and astrocytes in the mouse developing cortex. Neuron 37: 275-286.

41. Schmidt W, Wolf G (1988) High-affinity uptake of L-[3H]glutamate and D-[3H] aspartate during postnatal development of the hippocampal formation: quantitative autoradiographic study. Exp Brain Res 70: 50-54

42. Erdö SL, Wolff JR (1990) Postnatal development of the excitatory amino acid system in visual cortex of the rat. Changes in ligand binding to NMDA quisqualate and kainate receptors. Int J Dev Neurosci 8: 199-204.

43. Cohen SM, Nadler JV (1997) Sodium-dependent proline and glutamate uptake by hippocampal synaptosomes during postnatal development. Brain Res Dev Brain Res 100: 230-233.

44. Christensen H, Fonnum $F$ (1992) The ontogeny of the uptake systems for glutamate, GABA, and glycine in synaptic vesicles isolated from rat brain Neurochem Res 17: 457-462.

45. Sims KD, Robinson MB (1999) Expression patterns and regulation of glutamate transporters in the developing and adult nervous system. Crit Rev Neurobio 13: 169-197.

46. Heim C, Nemeroff CB (2002) Neurobiology of early life stress: clinical studies Semin Clin Neuropsychiatry 7: 147-159.

47. Gutman DA, Nemeroff CB (2002) Neurobiology of early life stress: roden studies. Semin Clin Neuropsychiatry 7: 89-95

48. Erecinska M, Cherian S, Silver IA (2004) Energy metabolism in mammalian brain during development. Prog Neurobiol 73: 397-445.

49. Acosta GB, Otero Losada ME, Rubio MC (1992) Changes in GABAergic function after chronic chemical stress. Gen Pharmacol 23: 241-244

50. Dowd LA, Coyle AJ, Rothstein JD, Pritchett DB, Robinson MB (1996) Comparison of $\mathrm{Na}$ +-dependent glutamate transport activity in synaptosomes, 
Citation: Odeon MM, Salatino AE, Acosta GB (2013) Consequences of Postnatal Stress: Maternal Separation in Rats Induces Long-Lasting Changes on Glutamate Transporters. Clin Exp Pharmacol 3: 121. doi:10.4172/2161-1459.1000121

C6 glioma, and Xenopus oocytes expressing excitatory amino acid carrier 1 (EAAC1). Mol Pharmacol 49: 465-473.

51. Guillet B, Lortet S, Masmejean F, Samuel D, Nieoullon A, et al. (2002) Developmental expression and activity of high affinity glutamate transporters in rat cortical primary cultures. Neurochem Int 40: 661-671.

52. Matsugami TR, Tanemura K, Mieda M, Nakatomi R, Yamada K, et al. (2006) From the Cover: Indispensability of the glutamate transporters GLAST and GLT1 to brain development. Proc Natl Acad Sci U S A 103: 12161-12166.

53. Robinson MB (1998) The family of sodium-dependent glutamate transporters: a focus on the GLT-1/EAAT2 subtype. Neurochem Int 33: 479-491.

54. Pryce CR, Rüedi-Bettschen D, Dettling AC, Weston A, Russig H, et al. (2005)
Long-term effects of early-life environmental manipulations in rodents and primates: Potential animal models in depression research. Neurosci Biobehav Rev 29: 649-674.

55. Ellenbroek BA, Cools AR (2000) The long-term effects of maternal deprivation depend on the genetic background. Neuropsychopharmacology 23: 99-106.

56. Holmes A, le Guisquet AM, Vogel E, Millstein RA, Leman S, et al. (2005) Early life genetic, epigenetic and environmental factors shaping emotionality in rodents. Neurosci Biobehav Rev 29: 1335-1346.

57. Sheldon AL, Robinson MB (2007) The role of glutamate transporters in neurodegenerative diseases and potential opportunities for intervention. Neurochem Int 51: 333-355. 